\title{
Reactor Production of Thorium-229
}

Susan Hogle ${ }^{1, *}$, Rose Ann Boll ${ }^{1}$, Karen Murphy ${ }^{1}$, David Denton ${ }^{1}$, Allison Owens ${ }^{1}$, Tamara J. Haverlock ${ }^{2}$, Marc Garland $^{1, \#}$, and Saed Mirzadeh ${ }^{1}$

Divisions of Nuclear Security and Isotopes Technology ${ }^{1}$, and Chemical Sciences ${ }^{2}$, Oak Ridge National Laboratory, Oak Ridge, TN 37831

*Corresponding Author: Hoglesl@ornl.gov

${ }^{\#}$ Current address. U.S. DOE Germantown

\begin{abstract}
Limited availability of ${ }^{229} \mathrm{Th}$ for clinical applications of ${ }^{213} \mathrm{Bi}$ necessitates investigation of alternative production routes. In reactor production, ${ }^{229} \mathrm{Th}$ is produced from neutron transmutation of ${ }^{226} \mathrm{Ra},{ }^{228} \mathrm{Ra},{ }^{227} \mathrm{Ac}$ and ${ }^{228} \mathrm{Th}$. Irradiations of ${ }^{226} \mathrm{Ra},{ }^{228} \mathrm{Ra}$, and ${ }^{227} \mathrm{Ac}$ targets at the Oak Ridge National Laboratory High Flux Isotope Reactor result in yields of ${ }^{229} \mathrm{Th}$ at 26 days of $74.0 \pm 7.4 \mathrm{MBq} / \mathrm{g}, 260 \pm 10 \mathrm{MBq} / \mathrm{g}$, and $1200 \pm 50 \mathrm{MBq} / \mathrm{g}$, respectively. Intermediate radionuclide yields and cross sections are also studied.

Key Words: Thorium-229; thorium-228; actinium-225; actinium-227; radium-226; radium-228; neutron reactions; Isochain; high flux isotope reactor.

This manuscript has been authored by UT-Battelle, LLC under Contract No. DE-AC05-000R22725 with the U.S. Department of Energy. The United States Government retains and the publisher, by accepting the article for publication, acknowledges that the United States Government retains a non-exclusive, paid-up, irrevocable, world-wide license to publish or reproduce the published form of this manuscript, or allow others to do so, for United States Government purposes. The Department of Energy will provide public access to these results of federally sponsored research in accordance with the DOE Public Access Plan(http://energy.gov/downloads/doe-public-access-plan).
\end{abstract}



A large number of antibody targeted radiopharmaceuticals are in development for the treatment of blood-borne cancers, disseminated cancers and a variety of solid tumors using alpha-emitters such as ${ }^{213} \mathrm{Bi},{ }^{225} \mathrm{Ac},{ }^{223} \mathrm{Ra},{ }^{227} \mathrm{Th}$ and ${ }^{211} \mathrm{At}$ (Miederer, 2008; Kim and Brechbiel, 2012). The alpha emitters combine high-potency, high-linear energy transfer, and low toxicity; consequently, the initial attempts to use alpha particles from alpha emitting radioisotopes have focused on leukemia and small micrometastatic deposits of cancer cells such as lymphoma. Among possible alpha emitters for application in targeted alpha therapy (TAT), interest in ${ }^{225} \mathrm{Ac}\left(\mathrm{t}_{1 / 2}=10.0\right.$ days) has increased substantially since the initial supply of this radioisotope from Oak Ridge National Laboratory (ORNL) in 1997 (Boll et al. 2005a; Du et al. 2003; Mirzadeh, 1998). Since then, ORNL has been the main supplier of high-purity ${ }^{225} \mathrm{Ac}$ from decay of existing ${ }^{229} \mathrm{Th}$ stock, and since $2011 \sim 26 \mathrm{GBq}$ of ${ }^{225} \mathrm{Ac}$ has been harvested annually from the ${ }^{229} \mathrm{Th}$ stock, typically in six campaigns per year. Supply of ${ }^{225} \mathrm{Ac}$, however, remains inadequate to meet the demand if current or planned clinical studies are found to be effective. Furthermore, the success of ${ }^{223} \mathrm{Ra}$ for treatment of metastatic prostate cancer, as the first alpha-emitting radiopharmaceutical approved by the U.S. Food and Drug Administration (Colletti, 2013), will further encourage the research and development (R\&D) of other alpha-emitting radiopharmaceutical therapies, including ${ }^{225} \mathrm{Ac}$, for clinical use. Efforts to increase the current production of ${ }^{225} \mathrm{Ac}$ and evaluate alternate production routes have been considered a high priority (Nuclear Science Advisory Committee, 2015), and in recent years a significant investment has been made in R\&D aimed at increasing the supply of ${ }^{225} \mathrm{Ac}$ (Mirzadeh, 2013; Jost et al. 2012; Weidner et al. 2012a, 2012b; Zhuikov et al. 2011; Apostolidis, 2005a, 2005b).

In this work, we report on a systematic evaluation of production of ${ }^{229} \mathrm{Th}$ via neutron irradiation of ${ }^{226} \mathrm{Ra},{ }^{227} \mathrm{Ac}$, and ${ }^{228} \mathrm{Ra}$ targets in the ORNL High Flux Isotope Reactor (HFIR), examining the nuclear reactions involved in multiple production pathways and assessing the future capacity for reactor supply of ${ }^{229} \mathrm{Th}$. Some preliminary data from this research were presented earlier (Boll et al. 2005b).

Production of ${ }^{229} \mathrm{Th}$ through neutron irradiation of ${ }^{226} \mathrm{Ra}$ requires three neutron captures and two $\beta^{-}$decays through a number of pathways, shown in Fig. 1 along with their associated nuclear data.

From the nuclear data presented in Fig. 1, it can be seen that the dominant production pathway is via:

${ }^{226} \mathrm{Ra} \stackrel{(n, \gamma)}{\longrightarrow}{ }^{227} \mathrm{Ra} \stackrel{\left(\beta^{-}\right)}{\longrightarrow}{ }^{227} \mathrm{Ac} \stackrel{(n, \gamma)}{\longrightarrow}{ }^{228} \mathrm{Ac} \stackrel{\left(\beta^{-}\right)}{\longrightarrow}{ }^{228} \mathrm{Th} \stackrel{(n, \gamma)}{\longrightarrow}{ }^{229} \mathrm{Th}$.

The amount of ${ }^{229} \mathrm{Th}$ produced from irradiation of ${ }^{226} \mathrm{Ra}$ can be calculated by solving a linked set of Bateman equations [1] of the form shown in equations (1) and (2).

$$
\begin{aligned}
& N_{i}(t)=\sum_{k=1}^{i}\left(\prod_{j=k}^{i-1} \Lambda_{j}\right) N_{k}^{0} \sum_{j=k}^{i} a_{j} e^{-\Lambda_{j} t} \\
& a_{j}=\prod_{m \neq j}\left(\Lambda_{m}-\Lambda_{j}\right)^{-1}(m=k, k+1, \ldots, i),
\end{aligned}
$$

Where:

$\Lambda_{i-1}$ is the formation rate constant $\left(\lambda_{\mathrm{i}-1}\right.$ or $\left.\sigma_{\mathrm{i}-1} \varphi\right)$ of the $\mathrm{i}^{\text {th }}$ species from the $(\mathrm{i}-1)^{\text {th }}$ species, $\Lambda_{i}$ is the total depletion rate constant $\left(\lambda_{i}+\sigma_{i} \varphi\right)$ of the $\mathrm{i}^{\text {th }}$ species. 

and Walsh, 1997), using the nuclear data given in Fig. 1, and the previously measured neutron fluxes in the HFIR hydraulic tube facility, listed in Table I (Mahmood et al. 1995). In this table and in all future references, the thermal to epithermal ratio, $\mathrm{R}$, refers to the ratio of the thermal flux to the flux in the energy range $0.5 \mathrm{eV}$ and $0.1 \mathrm{MeV}$ divided by the logarithm of the energy difference of that energy range, which is known as the flux per unit lethargy.

$$
R=\frac{\varphi_{\text {th }}}{\varphi_{\text {ep }} / \ln \left(\frac{E_{\text {Upper }}}{E_{\text {lower }}}\right)}
$$

In our computation, any unknown cross sections are assigned a value of 1 barn.

\begin{tabular}{|c|c|c|}
\hline $\begin{array}{l}\text { Hydraulic } \\
\text { Tube } \\
\text { Position }^{\text {a }}\end{array}$ & $\begin{array}{c}\text { Thermal } \\
\text { Flux } \\
\left(\mathrm{n} \cdot \mathrm{cm}^{-2} \cdot \mathrm{s}^{-1}\right)\end{array}$ & $\begin{array}{c}\text { Thermal - } \\
\text { Epithermal } \\
\text { Ratio }\end{array}$ \\
\hline 1 & $1.00 \times 10^{15}$ & 40 \\
\hline 2 & $1.45 \times 10^{15}$ & 35 \\
\hline 3 & $1.80 \times 10^{15}$ & 30 \\
\hline 4 & $2.00 \times 10^{15}$ & 25 \\
\hline 5 & $2.05 \times 10^{15}$ & 20 \\
\hline 6 & $1.95 \times 10^{15}$ & 25 \\
\hline 7 & $1.65 \times 10^{15}$ & 30 \\
\hline 8 & $1.20 \times 10^{15}$ & 35 \\
\hline
\end{tabular}

\section{Estimating Isotope Yields, Sensitivities and Uncertainties}

An initial calculation was performed to assess the potential for production of ${ }^{229} \mathrm{Th}$ from ${ }^{226} \mathrm{Ra}$ using a thermal neutron flux of $2.0 \times 10^{15} \mathrm{n} \cdot \mathrm{cm}^{-2} \cdot \mathrm{s}^{-1}$ and a thermal to epithermal flux ratio of 25 , representing the neutron flux in a typical target irradiation position near the mid-plane of the HFIR. This calculation was performed for 12 time steps of 25 days irradiation, with 35 days of decay between each time step, which is representative of $\sim$ two years' (12 cycles') worth of irradiation in HFIR. The production of ${ }^{229}$ Th over time is shown in Fig. 2. in units of GBq ${ }^{229} \mathrm{Th}$ per $\mathrm{g}{ }^{226} \mathrm{Ra}$ in the initial target.

From Fig. 2, it can be seen that the production of ${ }^{229} \mathrm{Th}$ is slow during the first cycle, fairly linear during the next five cycles, and then slowly leveling off before finally decreasing. Based on this analysis, the ideal irradiation period for production of ${ }^{229} \mathrm{Th}$ would be four to six cycles.

A sensitivity analysis was performed for the production of ${ }^{229} \mathrm{Th}$ from ${ }^{226} \mathrm{Ra}$ to identify the relative change in the yield of ${ }^{229}$ Th caused by a perturbation of a yield parameter such as the cross section of the precursor isotope. The sensitivity coefficient of the yield $\mathrm{Y}$ to the parameter $\mathrm{x}$ is given by equation 4 .

$$
S_{Y, x}=\frac{\delta_{Y} /_{Y}}{\delta_{x} / x}
$$



of ${ }^{228} \mathrm{Th}$, and the capture and fission cross sections of ${ }^{229} \mathrm{Th}$. While the transmutation chain generally proceeds through ${ }^{227} \mathrm{Ac}$, the sensitivity of ${ }^{229}$ Th to the cross section of ${ }^{227} \mathrm{Ac}$ is only $2.1 \%$. For example, if the ${ }^{227} \mathrm{Ac}[\mathrm{n}, \gamma]$ cross section was $10 \%$ greater than the value used in the calculations, this would result in only a $0.21 \%$ increase in the yield of ${ }^{229} \mathrm{Th}$ because the production of thorium is effectively throttled by the absorption rate in ${ }^{226} \mathrm{Ra}$. This work examines each of these contributing absorption reactions through a series of experiments of varying initial composition and irradiation duration. The sensitivity coefficient gives an indication of the importance of each precursor isotope cross section to the overall product yield. The cross sections and uncertainties used in the calculations presented in this paper were selected based on a review of various sources, including Mughabghab (2006), JENDL 3.3, Karlsruhe Chart of Nuclides, ENDF VII.0, KAPL Chart of Nuclides, and KAERI. These data and the calculated sensitivities for the main isotopes in the ${ }^{229} \mathrm{Th}$ production chain are shown in Table II.

Table II. Sensitivity and uncertainty of nuclear data

\begin{tabular}{ccccc}
\hline $\begin{array}{c}\text { Cross } \\
\text { Section }\end{array}$ & $\begin{array}{c}\text { Thermal } \\
(\mathrm{b})\end{array}$ & $\begin{array}{c}\text { Resonance } \\
\text { Integral } \\
(\mathrm{b})\end{array}$ & $\begin{array}{c}\text { Uncertainty } \\
(\%)\end{array}$ & $\begin{array}{c}\text { Sensitivity } \\
(\%)\end{array}$ \\
\hline${ }^{226} \mathrm{Ra}(\mathrm{n}, \gamma)$ & 12.78 & 285.6 & 11.7 & 41.9 \\
\hline${ }^{227} \mathrm{Ra}(\mathrm{n}, \gamma)$ & $457^{\mathrm{a}}$ & Unknown & Unknown & -0.5 \\
\hline${ }^{228} \mathrm{Ra}(\mathrm{n}, \gamma)$ & 36 & Unknown & 13.9 & 0.1 \\
\hline${ }^{227} \mathrm{Ac}(\mathrm{n}, \gamma)$ & 890 & 1650 & 2.6 & 2.1 \\
\hline${ }^{227} \mathrm{Th}(\mathrm{n}, \gamma)$ & 1535 & 1420 & Unknown & 0.0 \\
\hline${ }^{227} \mathrm{Th}(\mathrm{n}, \mathrm{f})$ & 202 & 210 & 6.4 & 0.0 \\
\hline${ }^{228} \mathrm{Th}(\mathrm{n}, \gamma)$ & 119.9 & 1160 & 11.1 & 20.1 \\
\hline${ }^{229} \mathrm{Th}(\mathrm{n}, \gamma)$ & 63.3 & 1236 & 13.8 & -31.2 \\
\hline${ }^{229} \mathrm{Th}(\mathrm{n}, \mathrm{f})$ & 31.6 & 446 & 11.7 & -15.2 \\
\hline${ }^{\mathrm{a}} \mathrm{This}$ work - See section III. & & \\
\hline
\end{tabular}

\section{EXPERIMENTAL}

\section{Radioactivity and Mass Measurements}

Radioactivity measurement was performed by $\gamma$-ray spectroscopy. Samples were assayed at a distance of 5 to $121 \mathrm{~cm}$ from a calibrated solid-state high-purity Ge detector $\left(50 \mathrm{~cm}^{3}\right.$, EG\&G Ortec, Oak Ridge, Tenn.) coupled to a PC-based multi-channel analyzer (MCA) employing GENIE software (Canberra Industries, Inc., Meriden, Conn.). The detector has a resolution of $1.0 \mathrm{keV}$ at $123 \mathrm{keV}$ and $1.8 \mathrm{keV}$ at $1332 \mathrm{keV}$. Energy and efficiency calibrations were determined with $\gamma$-ray sources traceable to the National Institute of Standards and Technology. Samples were counted with detector dead times not exceeding 10\%. Radioactivity (counts per second, cps) was converted to absolute disintegrations per second $\left(\mathrm{A}^{0}\right.$, dps $)$ by appropriate corrections for the $\gamma$-ray intensity and detector efficiency. The relevant radioisotopes were identified by observing $\gamma$ rays listed in Table AI of the Appendix. Since multiple $\gamma$-rays were utilized for assay, the inverse of their errors for the net count for each $\gamma$-ray peak was used as a weighting factor in calculating the average activity of each sample. This method of weighting was also used when assay results were averaged among different samples. Mass measurement was performed by quadrupole inductively coupled plasma mass spectrometry (ICP-MS) (Thermo X-SeriesII, Thermo Fisher Scientific, Franklin, Mass.). The sample introduction system consisted of a cooled spray chamber inlet system (PC3, Elemental Scientific Inc, Omaha, Nebr.). The system was further optimized for signal response and stability 
by monitoring oxide levels, mass responses and detector dead-time determinations via a tuning solution designed for this optimization process. Mass measurement was performed only on Ra targets and on chemically separated thorium fractions to determine isotopic ratios. All yields listed in this paper were decay corrected to the end of bombardment (EOB) in HFIR. The activities at EOB per unit mass of target, representing the production yield of the radionuclide, are reported in terms of $\mathrm{Bq}, \mathrm{kBq}$ or $\mathrm{MBq}$ per $\mu \mathrm{g}$ of the target material.

\section{Recovery of ${ }^{226}$ Ra from medical needles}

In a glovebox, a batch of Pt/Ir needles ( $2 \mathrm{~mm}$ OD and $20 \mathrm{~mm}$ length) each containing up to $\sim 200 \mathrm{MBq}$ of ${ }^{226} \mathrm{Ra}$ was transferred to a $250-\mathrm{mL}$ round bottom flask, and a mixture of $60 \% 10 \mathrm{M} \mathrm{HCl}$ and $40 \%$ concentrated $\mathrm{HNO}_{3}$ $(25 \mathrm{~mL})$ was added. The mixture was heated to boiling for several hours (under water cooled reflux) until the needle end cap was partially dissolved and separated from the needle body exposing the Ra salt. The radium containing solution was then transferred to a collection flask and an additional aliquot of $60 \% 10 \mathrm{M} \mathrm{HCl}$ and $40 \%$ concentrated $\mathrm{HNO}_{3}(25 \mathrm{~mL})$ added to the needles. The mixture was again heated to boiling under reflux for several hours and the solution then added to the previously collected batch of Ra. This process was repeated three further times and the radium containing solution collected. A water-cooled condenser was attached to the vessel containing the Ra solution and the solution evaporated to near dryness. An aliquot of $0.05 \mathrm{M} \mathrm{HCl} \mathrm{(100} \mathrm{mL)} \mathrm{was}$ added to the solution and the mixture evaporated close to dryness. Two further aliquots of $0.05 \mathrm{M} \mathrm{HCl}(100 \mathrm{~mL})$ were added and in each instance the solution evaporated close to dryness. The final condensate was then diluted with $0.05 \mathrm{M} \mathrm{HCl}$ to a volume of $\sim 800 \mathrm{~mL}$ and filtered through a glass-frit. The Ra containing solution $(\sim 0.05 \mathrm{M}$ $\mathrm{HCl}, 800 \mathrm{~mL}$ ) was loaded on a cation-exchange column (BioRad MP50 resin, $50 \mathrm{~mL} \mathrm{BV}$ ), and the column was washed with an additional $0.05 \mathrm{M} \mathrm{HCl}(100 \mathrm{~mL}$ ), followed by 4 bed volume (BV) (200 mL) of $4 \mathrm{M} \mathrm{HCl}$ to remove ${ }^{210} \mathrm{~Pb}$. The Ra was stripped from the column using $4 \mathrm{BV}$ of $7.5 M \mathrm{HNO}_{3}$, and the solution was evaporated to dryness and brought up in dilute $\mathrm{HNO}_{3}$ for use in target preparation.

\section{Recovery of ${ }^{228}$ Ra from ${ }^{232}$ Th stock}

The bulk separation of the Ra from Th was performed using ion exchange chromatography as described in Boll et al. (2005a). In brief, $600 \mathrm{~mL}$ bed volume column BioRad MP1 anion exchange resin (100-200 mesh) was used to process $\sim 50 \mathrm{~g}$ of Th. Thorium was loaded on the MP1 column in $8 M \mathrm{HNO}_{3}$, where Th as $\mathrm{Th}\left(\mathrm{NO}_{3}\right)_{5}\left(\mathrm{H}_{2} \mathrm{O}\right)^{-}$and $\mathrm{Th}\left(\mathrm{NO}_{3}\right)_{6}{ }^{2-}$ complexes are strongly retained while Ra ions are eluted. Subsequently, Th was eluted from the column with $0.1 \mathrm{M} \mathrm{HNO}_{3}$. A total of $\sim 4.4 \mathrm{~kg}$ of Th was processed in 95 runs reusing the same column. The ${ }^{228} \mathrm{Ra}$ fractions from each run were combined and evaporated to dryness and the resulting residue dissolved in a few milliliters of $8 \mathrm{M} \mathrm{HNO}_{3}$ and passed through a $0.5-\mathrm{mL} \mathrm{BV} \mathrm{MP-1} \mathrm{scavenging} \mathrm{column.}{ }^{228} \mathrm{Ra}$ was further purified from the bulk of lanthanides impurities present in the Th stock (as detected by neutron activation analysis) by loading the ${ }^{228} \mathrm{Ra}$ on an AG50X4 cation exchange column in $0.1 \mathrm{MHNO}_{3}$ and eluting the Ra with $10 \mathrm{BV}$ of $1.2 \mathrm{M}$ $\mathrm{HNO}_{3}$. Under the above conditions, the bulk of lanthanides remains on the column.

\section{Prepration of ${ }^{227}$ Ac target material}

Ac-227 target material was extracted from previously irradiated ${ }^{226} \mathrm{Ra}$ target, where the ${ }^{226} \mathrm{Ra}$ target solution was passed through a series of anion exchange (MP1/NO $)$ columns to separate Ac and Ra from Th, and then through a cation exchange column (AG50x4) to isolate actinium from radium and other cations, such as the lead and bismuth. The overall procedure was very similar to the procedure outlined above for the recovery of ${ }^{228} \mathrm{Ra}$ from ${ }^{232} \mathrm{Th}$. 


\section{Target Fabrication}

As part of this work, a total of thirteen targets were fabricated and irradiated in the HFIR. Composition and irradiation conditions for these targets are summarized in Table III. The largest effort was devoted to examination of neutron absorption in ${ }^{226} \mathrm{Ra}$ as this was the reaction having the greatest impact on the yield of ${ }^{229} \mathrm{Th} .{ }^{226} \mathrm{Ra}$ is also the proposed target material for increasing future ${ }^{229} \mathrm{Th}$ supplies because neither ${ }^{227} \mathrm{Ac}$ nor ${ }^{228} \mathrm{Ra}$ are available in appreciable quantities at this time. Furthermore, the complexity of manufacturing and qualifying production scale targets for irradiation at HFIR is inversely proportional to the half-lives of the target isotopes.

Table III. Composition and irradiation conditions for targets used in this study

\begin{tabular}{|c|c|c|c|c|c|}
\hline \multirow{2}{*}{$\begin{array}{l}\text { Target } \\
\text { ID }\end{array}$} & \multirow{2}{*}{$\begin{array}{l}\text { Effective } \\
\text { Hydraulic } \\
\text { Tube } \\
\text { Position }\end{array}$} & \multirow{2}{*}{$\begin{array}{l}\text { Irradiation } \\
\text { Duration } \\
\text { (d) }\end{array}$} & \multicolumn{3}{|c|}{ Target } \\
\hline & & & Isotope & Mass $(\mu \mathrm{g})$ & $\begin{array}{c}\text { Activity } \\
\text { (MBq) }\end{array}$ \\
\hline $1 \mathrm{a}$ & 5 & 26.09 & ${ }^{226} \mathrm{Ra}$ & 54.0 & 1.98 \\
\hline $1 \mathrm{~b}$ & 6 & 26.09 & ${ }^{226} \mathrm{Ra}$ & 51.0 & 1.86 \\
\hline $1 \mathrm{c}$ & 4 & 26.09 & ${ }^{226} \mathrm{Ra}$ & 48.4 & 1.77 \\
\hline $2 a$ & 3 & 26.09 & ${ }^{227} \mathrm{Ac}$ & 0.339 & 0.91 \\
\hline $2 b$ & 7 & 26.09 & ${ }^{227} \mathrm{Ac}$ & 0.401 & 1.07 \\
\hline $2 c$ & 1 & 26.09 & ${ }^{227} \mathrm{Ac}$ & 0.373 & 1.00 \\
\hline 3 & 6 & 25.00 & ${ }^{228} \mathrm{Ra}$ & 0.661 & 6.70 \\
\hline $4 a$ & 4 & 3.01 & ${ }^{226} \mathrm{Ra}$ & 50.1 & 1.83 \\
\hline $4 \mathrm{~b}$ & 6 & 3.01 & ${ }^{226} \mathrm{Ra}$ & 50.1 & 1.83 \\
\hline $5 a$ & 4 & 5.00 & ${ }^{226} \mathrm{Ra}$ & 49.3 & 1.81 \\
\hline $5 b$ & 6 & 5.00 & ${ }^{226} \mathrm{Ra}$ & 50.6 & 1.85 \\
\hline $6 a$ & 4 & 7.00 & ${ }^{226} \mathrm{Ra}$ & 50.1 & 1.83 \\
\hline $6 c$ & 6 & 7.00 & ${ }^{226} \mathrm{Ra}$ & 48.5 & 1.78 \\
\hline $7 a$ & 4 & 9.00 & ${ }^{226} \mathrm{Ra}$ & 29.4 & 1.08 \\
\hline $7 b$ & 6 & 9.00 & ${ }^{226} \mathrm{Ra}$ & 31.4 & 1.15 \\
\hline $8 a$ & 4 & 11.999 & ${ }^{226} \mathrm{Ra}$ & 30.7 & 1.12 \\
\hline $8 b$ & 6 & 11.999 & ${ }^{226} \mathrm{Ra}$ & 27.4 & 1.00 \\
\hline
\end{tabular}

Each target material was taken from a known volume of $0.1 M \mathrm{HNO}_{3}$, and a 5- $\mu \mathrm{L}$ aliquot was taken for assay to determine the activity concentration, i.e., $\mathrm{MBq} / \mu \mathrm{L}$. A specific volume of the solution was then pipetted to and dried down inside high-purity Suprasil® synthetic quartz ampoules $(6 \mathrm{~mm} \mathrm{OD,} 25 \mathrm{~mm} \mathrm{H}, \sim 0.3 \mathrm{~mm}$ wall thickness, Heraeus, Duluth, Ga.). The ampoules were flame sealed, and the precise amount of material in each ampoule was confirmed by $\gamma$-ray spectroscopy. The sealed ampoules were placed in $6061 \mathrm{Al}$ capsules $(51 \mathrm{~mm} \mathrm{H}$ and $6.7 \mathrm{~mm}$ diam) and welded shut under $\sim 1 \mathrm{~atm}$ He pressure.

\section{Post-Irradiation Handling of Targets}

Following irradiation, the targets were allowed to cool for approximately one month at the HFIR before transfer to the hot cell processing facility to allow for decay of short-lived fission and activation products, particularly those in the $\mathrm{Al}$ target capsule. Once transferred to the hot cell facilities, the Al capsules were cut open and the glass ampoules removed and transported to a glovebox. In the glovebox, the quartz ampoules were soaked in concentrated $\mathrm{HNO}_{3}$ for a few minutes and then thoroughly rinsed with deionized (D.I.) water to remove any surface contamination. 

whole units without any chemical manipulations. Target sets 1,2, and 3 were irradiated for a full 25+ day cycle, scored and broken, and the target materials were leached out of the glass, evaporated to dryness, and re-dissolved in $0.5 \mathrm{~mL}$ of $8 \mathrm{M} \mathrm{NHO}_{3}$. A 5- $\mu \mathrm{L}$ aliquot from each leached target was taken for analysis. The remainder of the target solution was subjected to extensive chemical processing, outlined below, to purify the thorium fraction from all other by-products, including ${ }^{212} \mathrm{~Pb}$ and ${ }^{212} \mathrm{Bi}$, the decay daughters of ${ }^{228} \mathrm{Th}$, which is present in an excess of 3000-fold at EOB. The separated Th fractions for target sets 1, 2, and 3 were then analyzed via $\gamma$-ray spectroscopy and ICP-MS.

\section{Extraction and purification of ${ }^{229}$ Th from irradiated targets}

To directly observe ${ }^{229} \mathrm{Th}$ by $\gamma$-ray spectroscopy, it is necessary to purify the thorium fraction from all other by-products, including ${ }^{212} \mathrm{~Pb}$ and ${ }^{212} \mathrm{Bi}$, the decay daughters of ${ }^{228} \mathrm{Th}$, which is present in a 3000 -fold excess at EOB. After dissolution of the target, the Th product was separated from target material and other by-products through two consecutive column chromatography runs. Similar to the ${ }^{228} \mathrm{Ra}$ recovery from ${ }^{232} \mathrm{Th}$ stock, Th was selectively retained on the anion exchange resin (MP-1 resin, BioRad Inc., 0.4-mL bed volume) from $8 M \mathrm{HNO}_{3}$ as nitrate complexes, while $\mathrm{U}(\mathrm{VI}), \mathrm{Ac}(\mathrm{III}), \mathrm{Fe}(\mathrm{III}), \mathrm{Al}(\mathrm{III}), \mathrm{Ra}(\mathrm{II})$ and $\mathrm{Pb}$ (II) and a number of fission products were eluted (Mirzadeh, 1984; 1986). The thorium fraction was eluted from this column with $0.1 \mathrm{M} \mathrm{HNO}_{3}$, evaporated to dryness, and the residue dissolved in $10 \mathrm{M} \mathrm{HCl}$ and loaded on a $0.4-\mathrm{mL} \mathrm{MP-1}$ column in $10 \mathrm{M} \mathrm{HCl}$, to remove additional fission products and traces of $\mathrm{U}$ and $\mathrm{Bi}$ ions. The load and wash solutions, containing purified Th, were combined, evaporated to near dryness, and dissolved in $0.5 \mathrm{~mL}$ of $8 M \mathrm{HNO}_{3}$. Just prior to $\gamma$-ray measurement, the Th fraction was loaded again on a 200- $\mu \mathrm{L} \mathrm{MP-1}$ column in $8 M \mathrm{HNO}_{3}$, and the column was washed with $\sim 10 \mathrm{BV}$ of $8 M \mathrm{HNO}_{3}$. When $>99 \%$ of the ${ }^{212} \mathrm{~Pb}$ was removed from the column (this was achieved by monitoring the intensity of the $238 \mathrm{keV} \gamma$-ray from ${ }^{212} \mathrm{~Pb}$ ), the Th fraction was eluted from the column with four BV of $0.1 \mathrm{MHNO}_{3}$, and a sample was assayed immediately at 5 to $10 \mathrm{~cm}$ from the detector. The activity of ${ }^{228} \mathrm{Th}$ in the sample, prior and post chemical separation, was used to calculate the chemical yield, which averaged $\sim 85 \%$. This procedure provided an approximate 12 -h window for the direct measurement of ${ }^{229} \mathrm{Th}$ by removing $>99 \%$ of the ${ }^{228} \mathrm{Th}$ decay daughters. Typical $\gamma$-ray spectra of the samples prior to chemical separation and post chemical separation are provide in Figure AI of Appendix.

\section{RESULTS}

\section{Evaluation of Primary ${ }^{229}$ Th Production Chain}

As discussed in the Introduction, the primary production pathway for formation of ${ }^{229} \mathrm{Th}$ is via three neutron capture reactions and two $\beta^{-}$decays through formation of the ${ }^{227} \mathrm{Ac}$ and ${ }^{228} \mathrm{Th}$ intermediate radionuclides.

\section{A. ${ }^{226} \mathrm{Ra}[n, \gamma]^{227} \mathrm{Ra}\left(t_{1 / 2}=42.2 \mathrm{~m}, \beta^{-}\right)^{227}$ Ac Reaction}

This reaction proceeds through formation of ${ }^{227} \mathrm{Ra}$, which quickly decays to ${ }^{227} \mathrm{Ac}$. Examination of ${ }^{227} \mathrm{Ac}$ production from ${ }^{226} \mathrm{Ra}$ was performed for the thirteen ${ }^{226} \mathrm{Ra}$ targets listed in Table III. The yields of ${ }^{227} \mathrm{Ac}$ are given as the activity per $\mu \mathrm{g}$ of original target at EOB in Table IV. The ratios of experimental to predicted yields are given in the last column of the table. The yields of ${ }^{227} \mathrm{Ac}$ ranged from $22.9 \pm 1.1 \mathrm{kBq} / \mu \mathrm{g}$ of ${ }^{226} \mathrm{Ra}$ for a 3 -day irradiation to $51.8 \pm 7.4$ for one cycle ( 26 days), and the average measured yield was $0.93 \pm 0.16$ of the predicted yield. While the yields were typically less than predicted, target set averages were within the uncertainty band, which accounts for uncertainties in the cross sections, neutron flux, $\gamma$-ray intensities, and detector efficiencies. Although the discrepancy between the measured and predicted yield may be due to an inaccuracy in the ${ }^{226} \mathrm{Ra}$ 
and/or ${ }^{227}$ Ac cross sections, other potential causes include a lower than expected neutron flux, increased absorption in ${ }^{227} \mathrm{Ra}$ resulting in greater than expected branching, and analytical errors during target fabrication and post-irradiation analysis.

Table IV. ${ }^{227}$ Ac yield from ${ }^{226} \mathrm{Ra}$ target as a function of irradiation time

\begin{tabular}{cccc}
\hline $\begin{array}{c}\text { Target } \\
\text { Set ID }\end{array}$ & $\begin{array}{c}\text { Irradiation } \\
\text { Duration } \\
\text { (day) }\end{array}$ & Yield $(\mathbf{k B q} / \boldsymbol{\mu g})$ & $\begin{array}{c}\text { Ratio of Measured } \\
\text { to Predicted Yield }\end{array}$ \\
\hline 4 & 3.01 & $22.9 \pm 1.1$ & $0.89 \pm 0.16$ \\
\hline 5 & 5.00 & $31.5 \pm 2.2$ & $0.85 \pm 0.15$ \\
\hline 6 & 7.00 & $45.1 \pm 2.2$ & $1.00 \pm 0.15$ \\
\hline 7 & 9.00 & $46.6 \pm 4.4$ & $0.92 \pm 0.14$ \\
\hline 8 & 11.999 & $50.7 \pm 4.8$ & $1.02 \pm 0.14$ \\
\hline 1 & 26.09 & $51.8 \pm 7.4$ & $0.85 \pm 0.22$ \\
\hline & Av. & $\mathbf{0 . 9 3} \pm \mathbf{0 . 1 6}$ \\
\hline
\end{tabular}

B. ${ }^{227} A c[n, \gamma]^{228} A c\left(t_{1 / 2}=6.15 h, \beta\right){ }^{228}$ Th Reaction

Due to the relatively short half-life of ${ }^{227} \mathrm{Ra}\left(\mathrm{t}_{1 / 2}=42.2 \mathrm{~min}\right)$, it is unlikely for this isotope to absorb a neutron prior to decay to ${ }^{227} \mathrm{Ac}$, even in a very high-flux environment. The fraction of ${ }^{227} \mathrm{Ra}$ which will transmute to ${ }^{228} \mathrm{Ra}$ vs. decaying to ${ }^{227} \mathrm{Ac}$ can be calculated using equation 5 .

$$
\text { Transmuted Fraction }=\frac{\varphi \sigma_{R a_{227}} N_{R a_{227}}}{\left(\varphi \sigma_{R a_{227}} N_{R a_{227}}+N_{R a_{227}} \lambda_{R a_{227}}\right)} \cong \frac{\varphi \sigma_{R a_{227}}}{\lambda_{R a_{227}}}
$$

Even with a cross section of $1.5 \mathrm{~kb}$ in a neutron flux of $2.0 \times 10^{15} \mathrm{n} \cdot \mathrm{cm}^{-2} \cdot \mathrm{s}^{-1}$, the transmuted fraction is only $1.1 \%$. If we further examine the transmuted fraction of ${ }^{227} \mathrm{Ac}$, replacing the parameters in equation (5) with those for ${ }^{227} \mathrm{Ac}$, this fraction is $99.9 \%$. As such, the predominant route from ${ }^{226} \mathrm{Ra}$ to ${ }^{229} \mathrm{Th}$ production involves the reaction $\left.{ }^{227} \mathrm{Ac}[\mathrm{n}, \gamma]\right]^{228} \mathrm{Ac}\left(\mathrm{t}_{1 / 2}=6.15 \mathrm{~h}, \beta^{-}\right){ }^{228} \mathrm{Th}$.

Examination of ${ }^{228} \mathrm{Th}$ production was performed both for ${ }^{226} \mathrm{Ra}$ targets via ${ }^{227} \mathrm{Ac}$ formation, and for ${ }^{227} \mathrm{Ac}$ targets directly. The production yields of ${ }^{228} \mathrm{Th}$ were measured for all thirteen ${ }^{226} \mathrm{Ra}$ targets and the three ${ }^{227} \mathrm{Ac}$ targets listed in Table III. The yields of ${ }^{228} \mathrm{Th}$ are given as the activity per $\mu \mathrm{g}$ of original target at EOB for both the ${ }^{226} \mathrm{Ra}$ targets and ${ }^{227} \mathrm{Ac}$ targets in Table $\mathrm{V}$. The ratios of experimental to predicted yields are given in the last column of each table. The average yields of ${ }^{228} \mathrm{Th}$ from ${ }^{226} \mathrm{Ra}$ and ${ }^{227} \mathrm{Ac}$ targets were $0.80 \pm 0.22$ and $0.97 \pm 0.09$ of the expected yields, respectively. There is greater uncertainty associated with the production of ${ }^{228} \mathrm{Th}$ from ${ }^{226} \mathrm{Ra}$ than from ${ }^{227} \mathrm{Ac}$ because of the multiple neutron capture reactions, with the ${ }^{226} \mathrm{Ra},{ }^{227} \mathrm{Ra},{ }^{227} \mathrm{Ac}$, and ${ }^{228} \mathrm{Th}$ cross sections, as well as the neutron flux, all contributing to the uncertainty of the theoretical prediction. 
Table V. ${ }^{228}$ Th yield from ${ }^{226}$ Ra and ${ }^{227}$ Ac targets

\begin{tabular}{|c|c|c|c|c|}
\hline \multicolumn{2}{|c|}{ Target } & \multirow{2}{*}{$\begin{array}{l}\text { Irradiation } \\
\text { Duration } \\
\text { (d) }\end{array}$} & \multirow{2}{*}{ Yield $(\mathrm{kBq} / \mu \mathrm{g})$} & \multirow{2}{*}{$\begin{array}{c}\text { Ratio of } \\
\text { Measured to } \\
\text { Predicted Yield } \\
(\%)\end{array}$} \\
\hline ID & Isotope & & & \\
\hline 4 & ${ }^{226} \mathrm{Ra}$ & 3.01 & $51.8 \pm 12.2$ & $0.71 \pm 0.29$ \\
\hline 5 & ${ }^{226} \mathrm{Ra}$ & 5.00 & $110 \pm 11$ & $0.62 \pm 0.20$ \\
\hline 6 & ${ }^{226} \mathrm{Ra}$ & 7.00 & $206 \pm 15$ & $0.67 \pm 0.19$ \\
\hline 7 & ${ }^{226} \mathrm{Ra}$ & 9.00 & $399 \pm 20$ & $0.90 \pm 0.25$ \\
\hline 8 & ${ }^{226} \mathrm{Ra}$ & 11.999 & $540 \pm 24$ & $1.06 \pm 0.27$ \\
\hline \multirow[t]{2}{*}{1} & ${ }^{226} \mathrm{Ra}$ & 26.09 & $1450 \pm 110$ & $0.78 \pm 0.16$ \\
\hline & & & Av. & $0.80 \pm 0.22$ \\
\hline 2 & ${ }^{227} \mathrm{Ac}$ & 26.09 & $18300 \pm 800$ & $0.97 \pm 0.09$ \\
\hline
\end{tabular}

\section{C. ${ }^{228} \mathrm{Th}[n, \gamma]^{229}$ Th Reaction}

The neutron capture in ${ }^{228} \mathrm{Th}$ is the final transmutation in the main production route for ${ }^{229} \mathrm{Th}$. Examination of ${ }^{229} \mathrm{Th}$ production from ${ }^{226} \mathrm{Ra}$ was performed for three ${ }^{226} \mathrm{Ra}$ targets and three ${ }^{227} \mathrm{Ac}$ targets, each irradiated for 26.09 days. At the time of this experiment, pure ${ }^{228} \mathrm{Th}$ was not available for this work; therefore, direct production of ${ }^{229} \mathrm{Th}$ from ${ }^{228} \mathrm{Th}$ was not examined, but it may be investigated in the future.

To directly observe ${ }^{229} \mathrm{Th}$ by $\gamma$-ray spectroscopy, the thorium fraction was chemically separated from the target materials, removing over $99 \%$ of the ${ }^{212} \mathrm{~Pb}$ daughters, and assayed immediately thereafter, as described in Chemical Processing. Because the presence of $\gamma$-rays directly from ${ }^{228} \mathrm{Th}$ and rapid ingrowth of daughters combined with the low activity of ${ }^{229} \mathrm{Th}$ leads to large uncertainties in the $\gamma$-ray spectroscopy, ICP-MS was also performed to further observe ${ }^{229} \mathrm{Th}$ production. The ratio of mass 229 to 228 was then multiplied by the measured value for ${ }^{228}$ Th determined via $\gamma$-ray spectroscopy to determine the amount of ${ }^{229} \mathrm{Th}$ with appropriate decay corrections. The yields of ${ }^{229} \mathrm{Th}$ are given as the activity per $\mu \mathrm{g}$ of original target at EOB for both the ${ }^{226} \mathrm{Ra}$ targets and ${ }^{227} \mathrm{Ac}$ targets in Table VI. The ratios of experimental to predicted yields are given in the last column of the table.

Table VI. ${ }^{229}$ Th yield from ${ }^{226}$ Ra and ${ }^{227}$ Ac targets ${ }^{\text {a }}$

\begin{tabular}{|c|c|c|c|c|}
\hline $\begin{array}{l}\text { Target } \\
\text { ID }\end{array}$ & Target & & $\begin{array}{c}\text { Yield } \\
(\mathrm{Bq} / \mu \mathrm{g})\end{array}$ & $\begin{array}{l}\text { Ratio of Measured } \\
\text { to Predicted Yield }\end{array}$ \\
\hline $1 \mathrm{a}$ & ${ }^{226} \mathrm{Ra}$ & & $81.4 \pm 7.4$ & $0.51 \pm 0.18$ \\
\hline $1 b$ & ${ }^{226} \mathrm{Ra}$ & & $55.5 \pm 3.7$ & $0.43 \pm 0.16$ \\
\hline \multirow[t]{2}{*}{$1 \mathrm{c}$} & ${ }^{226} \mathrm{Ra}$ & & $92.5 \pm 7.4$ & $0.71 \pm 0.26$ \\
\hline & & Av. & $74.0 \pm 7.4$ & $0.54 \pm 0.19$ \\
\hline $2 a$ & ${ }^{227} \mathrm{Ac}$ & & $1190 \pm 40$ & $0.52 \pm 0.08$ \\
\hline $2 b$ & ${ }^{227} \mathrm{Ac}$ & & $1350 \pm 70$ & $0.64 \pm 0.11$ \\
\hline \multirow[t]{2}{*}{$2 c$} & ${ }^{227} \mathrm{Ac}$ & & $988 \pm 56$ & $0.53 \pm 0.11$ \\
\hline & & Av. & $1200 \pm 50$ & $0.56 \pm 0.10$ \\
\hline
\end{tabular}

${ }^{a}$ Duration of irradiation $=26.09 \mathrm{~d}$. 
The average yields of ${ }^{229} \mathrm{Th}$ from ${ }^{226} \mathrm{Ra}$ and ${ }^{227} \mathrm{Ac}$ targets were $0.54 \pm 0.19$ and $0.56 \pm 0.10$ of the expected yields, respectively. There exists a large uncertainty in the expected yield of ${ }^{229} \mathrm{Th}$ owing to both significant uncertainties in the neutron capture cross sections for ${ }^{228} \mathrm{Th}$ and ${ }^{229} \mathrm{Th}$, in the range of 10 to $15 \%$ each (Table I), as well as the precursor cross section and neutron flux uncertainties discussed in the previous sections.

The ratio of mass 228 to 230 was also measured for the thorium fraction for each of these targets. For both the ${ }^{226} \mathrm{Ra}$ and ${ }^{227} \mathrm{Ac}$ targets the measured amount of ${ }^{230} \mathrm{Th}$ was in the range of $90 \% \pm 40 \%$ of the expected yield. This resulted in a much larger ratio of ${ }^{230} \mathrm{Th}$ to ${ }^{229} \mathrm{Th}$ than expected. Because the yield of ${ }^{230} \mathrm{Th}$ is much closer to the expected yield than ${ }^{229} \mathrm{Th}$, this may indicate that the capture and/or fission cross sections for ${ }^{229} \mathrm{Th}$ are higher than currently estimated. Similar results were seen by Kuznetsov et al. (2012), who reported ${ }^{229} \mathrm{Th}$ and ${ }^{230} \mathrm{Th}$ yields at $81 \%$ and $160 \%$ of the theoretical estimate during irradiation of ${ }^{226} \mathrm{Ra}$ in the high-flux SM reactor in Russia.

\section{Evaluation of Secondary ${ }^{229}$ Th Production Chain}

In addition to the main production pathway through ${ }^{227} \mathrm{Ac}$ and ${ }^{228} \mathrm{Th}$, some small amount of ${ }^{229} \mathrm{Th}$ may be produced through alternate routes. To quantify the effects of these alternative routes, absorption in the secondary precursor isotopes ${ }^{227} \mathrm{Ra}$ and ${ }^{228} \mathrm{Ra}$ was examined.

\section{A. ${ }^{227} \operatorname{Ra}[n, \gamma]{ }^{228} \operatorname{Ra}\left(t_{1 / 2}=5.75 y, \beta^{-}\right){ }^{228}$ Ac Reaction}

Neutron absorption in secondary precursor isotope ${ }^{227} \mathrm{Ra}$ was addressed by examining the level of ${ }^{228}$ Ra present in the irradiated ${ }^{226} \mathrm{Ra}$ targets. The measured yields of ${ }^{228} \mathrm{Ra}$ in each target are listed in Table VII as the activity per $\mu \mathrm{g}$ of original target at EOB for each of the ${ }^{226} \mathrm{Ra}$ targets, along with the calculated effective cross section for ${ }^{227} \mathrm{Ra}$. The effective cross sections of ${ }^{227} \mathrm{Ra}$ corresponding to the measured average activity of ${ }^{228} \mathrm{Ra}$ for each group (column 3 of Table VII) were empirically determined by using code IsoChain (see Introduction). The average value of the infinitely dilute effective cross section for ${ }^{227} \mathrm{Ra}$ was determined to be $457 \pm 195 \mathrm{~b}$. The relatively large error associated with this cross section is primarily due to propagation of uncertainties. The calculation of ${ }^{227} \mathrm{Ra}$ cross section is dependent on cross sections of both ${ }^{226} \mathrm{Ra}$ and ${ }^{228} \mathrm{Ra}$ and neutron flux. Therefore, uncertainties in those values are also propagated in calculation of ${ }^{228} \mathrm{Ra}$ cross section uncertainty. Under a typical thermal flux of $2 \times 10^{15} \mathrm{n} \cdot \mathrm{cm}^{-2} \cdot \mathrm{s}^{-1}$, the fraction of ${ }^{227} \mathrm{Ra}$ which will transmute to ${ }^{228} \mathrm{Ra}$ is $0.32 \%$, as calculated using equation 5 from Section III.B. Although the cross section of ${ }^{227} \mathrm{Ra}$ appears to be quite large, because of the very short half-life, very little material is converted to ${ }^{228} \mathrm{Ra}$ as a fraction of the total target. This confirms the results of the sensitivity analysis, which indicated that the production of ${ }^{229} \mathrm{Th}$ is not highly sensitive to the cross section of ${ }^{227} \mathrm{Ra}$. 
Table VII. Yield of ${ }^{228} \mathrm{Ra}$ from ${ }^{226} \mathrm{Ra}$ target

\begin{tabular}{|c|c|c|c|}
\hline ID & $\begin{array}{c}\text { Irradiation } \\
\text { Duration }\end{array}$ & Yield $(\mathrm{Bq} / \mu \mathrm{g})$ & $\begin{array}{l}\text { Effective Cross } \\
\text { Section (b) }\end{array}$ \\
\hline
\end{tabular}

(d)

\begin{tabular}{cccc}
\hline 4 & 3.01 & $392 \pm 78$ & $434 \pm 231$ \\
\hline 5 & 5.00 & $740 \pm 33$ & $500 \pm 191$ \\
\hline 6 & 7.00 & $999 \pm 44$ & $495 \pm 185$ \\
\hline 7 & 9.00 & $1470 \pm 70$ & $525 \pm 203$ \\
\hline 8 & 11.99 & $1460 \pm 60$ & $441 \pm 162$ \\
\hline 1 & 26.09 & $2430 \pm 520$ & $346 \pm 188$ \\
\hline & Av. & $\mathbf{4 5 7} \pm \mathbf{1 9 5}$ \\
\hline
\end{tabular}

B. ${ }^{228} \mathrm{Ra}[\mathrm{n}, \gamma]^{229} \mathrm{Ra}\left(t_{1 / 2}=4.0 \mathrm{~min}, \beta^{-}\right)^{229} \mathrm{Ac}\left(t_{1 / 2}=1.04 \mathrm{~h}, \beta^{-}\right)^{229} \mathrm{Th}$ Reaction

The neutron capture in ${ }^{228} \mathrm{Ra}$ is the final transmutation in this secondary production route for ${ }^{229} \mathrm{Th}$. Obviously, due to the relatively short half-lives of ${ }^{229} \mathrm{Ra}\left(\mathrm{t}_{1 / 2}=4 \mathrm{~min}\right)$, and ${ }^{229} \mathrm{Ac}\left(\mathrm{t}_{1 / 2}=1.04 \mathrm{~h}\right)$, the majority of ${ }^{229} \mathrm{Ra}$ produced decays by two successive $\beta^{-}$emissions to ${ }^{229} \mathrm{Th}$. Although the results of the previous section indicated that very little ${ }^{226} \mathrm{Ra}$ is converted to ${ }^{228} \mathrm{Ra}$ through ${ }^{227} \mathrm{Ra}$, there may be small amounts present in the original ${ }^{226} \mathrm{Ra}$ target material. Additionally, if radium from the irradiated targets is recycled to form new targets, the presence of ${ }^{228} \mathrm{Ra}$ will increase for future targets. The result of ${ }^{229} \mathrm{Th}$ production from ${ }^{228} \mathrm{Ra}$ was based on a single measurement of $0.661 \pm 0.007 \mu \mathrm{g}(6.70 \pm 0.07 \mathrm{MBq}){ }^{228} \mathrm{Ra}$ for a target (Target 3, Table III) that was irradiated for 25.5 days. The target, however, also contained $0.20 \mu \mathrm{g}$ of ${ }^{226} \mathrm{Ra}$. The mass spectrum of the ${ }^{228} \mathrm{Ra}$ target prior to irradiation is shown in Fig. 3 (upper). Note that natural thorium typically contains small amounts of ${ }^{230} \mathrm{Th}$, which decays to ${ }^{226} \mathrm{Ra}$.

After irradiation, the thorium fraction was isolated and purified as described earlier. However, two additional passes over the MP-1/NO $\mathrm{NO}_{3}$ column were necessary for removal of the Eu isotope impurities. Europium isotopes originated from contamination of the ${ }^{228} \mathrm{Ra}$ target with $\sim 7 \mu \mathrm{g}$ of ${ }^{153} \mathrm{Eu}$ (initially present in the ${ }^{232} \mathrm{Th}$ stock, see Experimental), resulting in production of a large number of Eu isotopes which must be chemically removed.

Post-irradiation examination of the ${ }^{228} \mathrm{Ra}$ target by $\gamma$-ray spectroscopy indicated that there was $5.37 \pm 0.26 \mathrm{MBq}$ of ${ }^{228} \mathrm{Ra}$ remaining in the target, which was $99 \%$ of the expected theoretical value, and $0.81 \mathrm{MBq}$ of ${ }^{228} \mathrm{Th}$. Of this total ${ }^{228} \mathrm{Th}$ activity, $0.34 \mathrm{MBq}$ was expected to be from ingrowth from ${ }^{228} \mathrm{Ra}$, leaving a corrected yield of $0.47 \mathrm{MBq}$ from the ${ }^{226} \mathrm{Ra}$ production chain. The relative amounts of each thorium isotope were determined via mass spectroscopy of the purified Th fraction, shown in Fig. 3 (lower), which was combined with the measured amount of ${ }^{228} \mathrm{Th}$ to determine a total yield. For ${ }^{229} \mathrm{Th}$ and ${ }^{230} \mathrm{Th}$, only $\sim 3 \%$ of the yield is expected to be due to the ${ }^{226} \mathrm{Ra}$ production chain, with the remaining produced via neutron capture by ${ }^{228} \mathrm{Ra}$. As such, the yields of ${ }^{229} \mathrm{Th}$ and ${ }^{230} \mathrm{Th}$ are shown in Table VIII as the activity at EOB per $\mu \mathrm{g}$ of ${ }^{228} \mathrm{Ra}$ in the original target, while the yield of ${ }^{228} \mathrm{Th}$ is shown as the activity at EOB per $\mu \mathrm{g}$ of ${ }^{226} \mathrm{Ra}$. 
The corrected yield of ${ }^{228} \mathrm{Th}$ from ${ }^{226} \mathrm{Ra}$ is lower than expected and similar to what was found with the pure ${ }^{226} \mathrm{Ra}$ targets. The yield of ${ }^{229} \mathrm{Th}$ at $260 \pm 10 \mathrm{~Bq} / \mu \mathrm{g}$ of ${ }^{228} \mathrm{Ra}$ is significantly below the expected value of $\sim 1000 \mathrm{~Bq} / \mu \mathrm{g}$. At this time, the cause of the discrepancy is unknown, particularly with both the ${ }^{228} \mathrm{Ra}$ and ${ }^{230} \mathrm{Th}$ yields much closer to the expected value. The discrepancy may be due to extremely high cross section of ${ }^{229} \mathrm{Ac}$, followed by rapid transmutation of ${ }^{230} \mathrm{Ac}$ to ${ }^{230} \mathrm{Th}$. The discrepancy may also be as a result of fission of ${ }^{229} \mathrm{Th}$, or analytical errors, and in part due to the Eu contamination. Note that our theoretical calculations include a 30-b cross section for fission of ${ }^{229} \mathrm{Th}$ [Table II]; therefore, further evaluation of this production route and re-evaluation of the fission cross section of ${ }^{229} \mathrm{Th}$ is necessary. Furthermore, due to contamination of the ${ }^{228} \mathrm{Ra}$ target with $\sim 7 \mu \mathrm{g}$ of ${ }^{153} \mathrm{Eu}$ and the presence of a large number of Eu isotopes, including 400 to $600 \mathrm{MBq}$ of ${ }^{156} \mathrm{Eu}$, it was impossible to identify any fission products, which were expected to be present in only very small amounts.

\section{DISCUSSION}

As discussed in the previous sections, for one HFIR cycle ( 26 days), the yields of ${ }^{229}$ Th from ${ }^{226} \mathrm{Ra}$ and ${ }^{227} \mathrm{Ac}$ targets are $74.0 \pm 7.4 \mathrm{MBq} / \mathrm{g}$ and $1200 \pm 50 \mathrm{MBq} / \mathrm{g}$, respectively. For the ${ }^{226} \mathrm{Ra}$ target, the ratio of measured to predicted yield was $0.54 \pm 0.19$, and for the ${ }^{227} \mathrm{Ac}$ target this ratio was $0.56 \pm 0.10$. The yield of ${ }^{229} \mathrm{Th}$ from ${ }^{228} \mathrm{Ra}$ in a single measurement was $260 \pm 10 \mathrm{MBq} / \mathrm{g}$, which is only $24 \%$ of the expected yield. Large absorption in ${ }^{227} \mathrm{Ra}$ will result in lower than expected ${ }^{229} \mathrm{Th}$ yields if the absorption cross section of ${ }^{228} \mathrm{Ra}$ is significantly lower than that of ${ }^{228} \mathrm{Th}$. However, as discussed in Section II.B, this would require an extremely high ${ }^{227}$ Ra cross section. Absorption in ${ }^{228} \mathrm{Ac}$ at this time has not been investigated because the primary effect of a large ${ }^{228} \mathrm{Ac}$ absorption cross section would be a higher than expected yield of ${ }^{229} \mathrm{Th}$ and a lower than expected yield of ${ }^{228} \mathrm{Th}$, which has not been observed.

Our collective data for the yields of radionuclides from the ${ }^{226} \mathrm{Ra}$ targets indicate that while experimental yields are generally below the calculated values, each radionuclide yield falls within the theoretical bounds based on the maximum and minimum expected neutron fluxes in the HFIR hydraulic tube. These bounds, and the experimental yields reported in this paper, together with the experimental yields reported earlier (Boll, 2005b) are shown in Fig. 4.

A single data point for ${ }^{229} \mathrm{Th}$ production at 18.5 days is a significant outlier. Most likely this target was contaminated with traces of ${ }^{229} \mathrm{Th}$ during chemical processing, and as such this data point is not used to make future projections for ${ }^{229} \mathrm{Th}$ yields. If the average ${ }^{229} \mathrm{Th}$ experimental yields from this work are extrapolated using the production curve trend from Fig. 1, it is estimated that 400 to $500 \mathrm{MBq}^{229} \mathrm{Th}$ per gram of ${ }^{226} \mathrm{Ra}$ can be produced in four 25-day irradiation cycles in the ORNL HFIR. As briefly discussed in the Introduction, based on 
our analysis depicted in Fig. 2, the ideal irradiation period for production of ${ }^{229}$ Th would be four to six cycles. The end of bombardment activities of ${ }^{228} \mathrm{Th}$ and ${ }^{227}$ Ac contaminants, which are co-produced with ${ }^{229} \mathrm{Th}$, are estimated to be $\sim 4000$ and $\sim 60$ times larger, respectively, after four irradiation cycles. For six-cycle irradiations, the projected ${ }^{229} \mathrm{Th}$ is only $6 \%$ higher than the four-cycle projections, at 420 to $520 \mathrm{MBq}$ per gram of ${ }^{226} \mathrm{Ra}$, with ${ }^{228} \mathrm{Th}$ and ${ }^{227} \mathrm{Ac}$ contaminations 3000 and 50 times larger than ${ }^{229} \mathrm{Th}$. However, because the yields of thorium isotopes were generally lower than expected in these experiments, it may be possible that transmutation is happening more slowly than projected, in which case the gains in yields from longer irradiation would increase. In any of the scenarios, high-purity ${ }^{225} \mathrm{Ac}$ can be obtained from the thorium mixture as ${ }^{228} \mathrm{Th}$ does not decay through actinium. Typically, radium is also extracted from the thorium cow for additional production of ${ }^{225} \mathrm{Ac}$ due to decay of ${ }^{225} \mathrm{Ra}$. Important to note that co-production of high levels of ${ }^{228} \mathrm{Th}$ and elevated levels of radiation dose from the emission of intense and high energy $\gamma$-rays in the ${ }^{228} \mathrm{Th}$ decay chain, requires extensive shielding and an adequate ventilation system to handle the emission of $56-\mathrm{s}{ }^{220} \mathrm{Rn}$. The effect of radiolysis due to high level of ${ }^{228} \mathrm{Th}$ in the mixture, however, can be dealt with by diluting the mixture with natural ${ }^{232} \mathrm{Th}$, similar to the current ORNL ${ }^{229} \mathrm{Th}$ stock which is composed of $99.6 \%{ }^{232} \mathrm{Th}$ and $0.4 \%{ }^{229} \mathrm{Th}$ (Boll et al, 2005).

Collective data for the yields of radionuclides from the ${ }^{227} \mathrm{Ac}$ targets as well as the theoretical bounds based on the maximum and minimum expected neutron fluxes in the HFIR hydraulic tube are shown in Fig. 5. As seen, while ${ }^{228} \mathrm{Th}$ yields are generally within the bounds, the yields of ${ }^{229} \mathrm{Th}$ fall below the lower bound for all three targets. Extrapolating the measured ${ }^{229} \mathrm{Th}$ production data following the theoretical curve, it is estimated that 1100 to $1500 \mathrm{MBq}{ }^{229} \mathrm{Th}$ per gram of ${ }^{227} \mathrm{Ac}$ can be produced in two 25-day irradiation cycles, with EOB activities of ${ }^{228} \mathrm{Th}$ 3000 times larger.

Finally, ${ }^{229} \mathrm{Th}$ yields from the single ${ }^{228} \mathrm{Ra}$ target were much lower than the theoretical minimum. Because of the difficulty performing $\gamma$-ray spectroscopy in the presence of significant Eu contamination, there is much uncertainty regarding these results, and further evaluation is recommended.

Three key areas of future study necessary to further refine the production capability for ${ }^{229} \mathrm{Th}$ are: (1) examination of ${ }^{228} \mathrm{Th}[\mathrm{n}, \gamma]$ cross section; (2) evaluation of ${ }^{229} \mathrm{Th}[\mathrm{n}, \gamma]$ and [n,f] cross sections; and (3) re-evaluation of ${ }^{228} \mathrm{Ra}$ $[\mathrm{n}, \gamma]{ }^{229} \mathrm{Ra}\left(\mathrm{t}_{1 / 2}=4.0 \mathrm{~m}, \beta^{-}\right){ }^{229} \mathrm{Ac}\left(\mathrm{t}_{1 / 2}=1.05 \mathrm{~h}, \beta^{-}\right){ }^{229} \mathrm{Th}$ production pathway. Irradiation of a highly pure sample of ${ }^{228} \mathrm{Th}$ containing dilute flux monitors is proposed to address these first two needs. Measuring the production of ${ }^{229} \mathrm{Th}$ and ${ }^{230} \mathrm{Th}$ in this target will address the capture cross sections, while measuring the fission products in the sample that will contain negligible amounts of highly fissile ${ }^{227} \mathrm{Th}$ will address the fission cross section of ${ }^{229} \mathrm{Th}$. The inclusion of a flux monitor will additionally help reduce the uncertainty in the neutron flux in these irradiations. Recycling of the previously irradiated ${ }^{228} \mathrm{Ra}$ sample is proposed to address the third need.

\section{ACKNOWLEDGEMENTS}

The ORNL Reactor Division, in particular Mr. G. Hirtz for his assistance related to the irradiation planning and scheduling is acknowledged with appreciation. The authors acknowledge Dr. Roy Copping and Dr. Steve Sherman for their critical review of the manuscript.

This research is supported by the Isotope Program, Office of Nuclear Physics of the U.S. Department of Energy. ORNL is managed by UT-Battelle, LLC, for the U.S. Department of Energy under contract DE-AC05-00OR22725. 


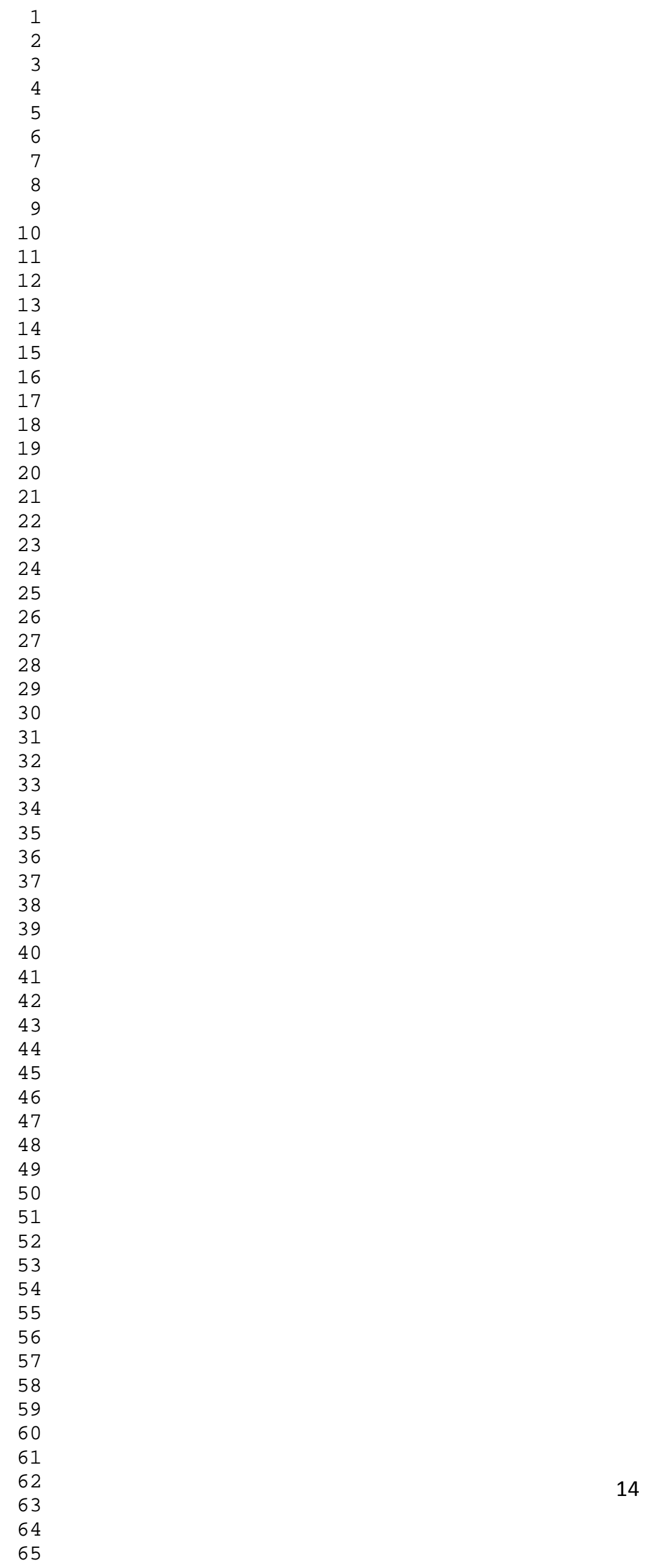




\section{APPENDIX}

Table A1. Gamma Rays Used for Assay of Key Isotopes ${ }^{\text {a }}$

\begin{tabular}{|c|c|c|c|}
\hline \multirow[b]{2}{*}{$\begin{array}{l}\text { Radionuclide } \\
\text { Quantified }\end{array}$} & \multirow[b]{2}{*}{$\begin{array}{l}\text { Radionuclide } \\
\text { Observed }\end{array}$} & \multicolumn{2}{|c|}{ Gamma-ray } \\
\hline & & $\begin{array}{c}\text { Energy } \\
(\mathrm{keV})\end{array}$ & $\begin{array}{l}\text { Absolute } \\
\text { Intensity } \\
\quad(\%)\end{array}$ \\
\hline${ }^{226} \mathrm{Ra}$ & ${ }^{226} \mathrm{Ra}$ & 186.1 & 3.28 \\
\hline \multirow{6}{*}{${ }^{227} \mathrm{Ac}$} & 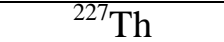 & 236.0 & 11.05 \\
\hline & & 256.2 & 6.61 \\
\hline & & 300.0 & 2.07 \\
\hline & & 329.8 & 2.69 \\
\hline & & 334.4 & 0.976 \\
\hline & ${ }^{223} \mathrm{Ra}$ & 269.4 & 13.6 \\
\hline \multirow[t]{3}{*}{${ }^{228} \mathrm{Ra}$} & ${ }^{228} \mathrm{Ac}$ & 338.4 & 12.4 \\
\hline & & 911.2 & $29.0 ?$ \\
\hline & & 969.0 & 17.4 \\
\hline \multirow[t]{5}{*}{${ }^{228} \mathrm{Th}$} & ${ }^{228} \mathrm{Th}$ & 131.5 & 0.128 \\
\hline & & 166.4 & 0.082 \\
\hline & & 205.8 & 0.028 \\
\hline & & 215.8 & 0.277 \\
\hline & ${ }^{224} \mathrm{Ra}$ & 240.8 & 3.9 \\
\hline \multirow[t]{2}{*}{${ }^{229} \mathrm{Th}$} & ${ }^{229} \mathrm{Th}$ & 193.6 & 4.41 \\
\hline & & 210 & 2.97 \\
\hline \multicolumn{4}{|c|}{$\begin{array}{l}{ }^{a} \text { Absolute intensities of } \gamma \text { rays include corrections for } \\
\text { branching ratios. The branching ratios were } 100 \% \text { for all } \\
\gamma \text { rays except those from }{ }^{227} \mathrm{Th} \text {, where the branching ratio was } \\
98.62 \% \text {. }\end{array}$} \\
\hline
\end{tabular}

\section{REFERENCES}

Almanza, C. et al., 2006. IsoChain: A User-Friendly, Two-Group Nuclear Transmutation and Decay Code. American Nuclear Society Transactions, Vol. 95, No. 1, 441-442.

Apostolidis, C., Molinet, R., McGinly, J., Abbas, K., Möllenbeck, J., Morgenstern, A., 2005a. Cyclotron production of Ac-225 for targeted alpha therapy. Appl. Radiat. Isot., 62, 383.

Apostolidis C, Molinet R, Rasmussen G, Morgenstern A., 2005b. Production of Ac-225 from Th-229 for targeted alpha therapy. Analytical Chemistry, 77, 6288.

Bateman H., 1910. Solution of a system of differential equations occurring in the theory of radioactive transformations. Proc. Cambridge Philos. Soc., 15, 423-427.

Boll, R.A., Malkemus, D., Mirzadeh, S., 2005a. Production of actinium-225 for alpha particle mediated radioimmunotherapy. Applied Radiation and Isotopes, 62, 667-679.

Boll, R. A., Garland, G., Mirzadeh, S., 2005b. Reactor Production of Thorium-229. Proceedings of the International Conference on Nuclear Data for Science and Technology, Santa Fe, New Mexico, USA, 

1675.

Colletti, P. M., 2013. New Treatment Option: ${ }^{223}$ Ra Chloride, the First Approved Unsealed $\alpha$-emitting Radiopharmaceutical. Clinical Nuclear Medicine, 38(9), 724-5.

Du, M., Peretz, F., Boll, R. A., Mirzadeh, S., 2003. Purification of Thorium-229 for Medical Applications. Proceedings of Symposium on Radioanalytical Methods in Interdisciplinary Research, $233^{\text {rd }}$ American Chemical Society National meeting, Orlando, Fla., April 10, 2002. ACS Symposium No. 868, C. A. Laue and K. L. Nash editors, American Chemical Society, WDC, 193-203.

Jost, C. U., Griswold, J. R., Bruffey, S. H., Stracener, D. W., Williams, C. L. Mirzadeh, S., 2012. Measurement of cross sections for the ${ }^{232} \mathrm{Th}[\mathrm{p}, 4 \mathrm{n}]^{229} \mathrm{~Pa}$ reaction at low proton energies. In Proceedings of $22^{\text {nd }}$ International Conference on the Application of Accelerators in Research and Industry, August 5 - 10, 2012, Fort Worth, Texas.

Kim, Y. S., Martin W. Brechbiel, 2012. An overview of targeted alpha therapy. Tumor Biology, 33 (3), 573.

Kuznetsov, R. A., Butkalyuk, P. S., Tarasov, V. A., Baranov, A. Yu., Butkalyuk, I. L., Romanov, E. G., Kupriyanov, V. N., Kazakova, E. V., 2012. Yields of Activation Products in ${ }^{226}$ Ra Irradiation in the High-Flux SM Reactor. Radiochemistry, 54 (4), 383-387.

Mahmood, S. T., Mirzadeh, S., Farrell, K., Pace, J. V., Oliver, B. M., 1995. Neutron Dosimetry of the HFIR Hydraulic Facility. ORNL/TM-12831, Lockheed Martin Energy Systems, Inc., Oak Ridge National Laboratory.

Miederer, M., Scheinberg, D. A., McDevitt, M. R., 2008. Realizing the potential of the Actinium-225 radionuclide generator in targeted alpha-particle therapy applications. Adv Drug Deliv Rev., 60(12), 371.

Mirzadeh, S., 2013. Accelerator Produced ${ }^{225}$ Ac via Proton Spallation of ${ }^{232}$ Th: A Joint Research Program Among ORNL, LANL, and BNL. ORNL/TM-2013/142, UT-Battelle, Inc., Oak Ridge National Laboratory.

Mirzadeh, S., 1998. Generator-produced Alpha-emitters. Proceedings of CIRMS Medical Subcommittee Workshop on Radionuclides Used in Bone Pain Palliation Therapy. National Institute of Standards and Technology, Washington, D.C., September 27, 1996. Applied Radiation and Isotopes, 49, 345-349.

Mirzadeh, S., Chu, Y. Y., Katcoff, S., Peker, L. K., 1984. Decay of 37.5-min Th-236 and 9.1-min Pa-236, Journal of Physical Review C, 29, 985.

Mirzadeh, S., Chu, Y. Y., Katcoff, S., Peker, L. K., 1986. Decay of 7.1-min Th-235, Journal of Physical Review $C, \mathbf{3 3}, 2159$.

Mirzadeh, S., Walsh, P., 1997. Numerical evaluation of the production of radionuclides in a nuclear reactor Parts I \& II. Applied Radiation and Isotopes, 49(4), 379-382 and 383-395.

Mughabghab, S. F., 2006. Atlas of Neutron Resonances. Elsevier BV.

Nuclear Science Advisory Committee, 2015. The 2015 Long Range Plan for Nuclear Science. 

Fassbender, M. E., Godd, G. S., Gritzo, R., Hemez, F. M., Runde, W., Ullmann, J. L., Wolfsberg, L. E., Nortier, F. M., 2012a. ${ }^{225} \mathrm{Ac}$ and ${ }^{223}$ Ra production via $800 \mathrm{MeV}$ proton irradiation of natural thorium targets. Applied Radiation and Isotopes, 70, 2590.

Weidner, J. W., Mashnik, S. G., John, K. D., Hemez, F., Ballard, B., Bach, H., Birnbaum, E. R., Bitteker, L. J., Couture, A., Dry, D., Fassbender, M. E., Gulley, M. S., Jackman, K. R., Ullmann, J. L., Wolfsberg, L. E., Nortier, F. M., 2012b. Proton-induced cross sections relevant to production of ${ }^{225} \mathrm{Ac}$ and ${ }^{223} \mathrm{Ra}$ in natural thorium targets below $200 \mathrm{MeV}$. App. Rad. Isotopes, 70, 2602.

Zhuikov, B. L., Kalmykov, S. N., Ermolaev, S. V., Aliev, R. A., Kokhanyuk, V. M., Matushko, V. L., Tananaev, I. G., Myasoedov, B. F., 2011. Production of ${ }^{225} \mathrm{Ac}$ and ${ }^{223}$ Ra by Irradiation of Th with Accelerated Protons. Radiochemistry, 53, 73.

\section{CAPTIONS TO FIGURES}

Fig. 1. Transmutation pathways from ${ }^{226} \mathrm{Ra}$ to ${ }^{229} \mathrm{Th}$ and approximate neutron cross sections. As indicated, the first term of cross section refers to thermal and second term to resonance integrals. The values in parenthesis are fission cross sections at thermal and epi-thermal neutrons, respectively.

Fig. 2. Theoretical production of ${ }^{229} \mathrm{Th}$ from ${ }^{226} \mathrm{Ra}$ target at the ORNL HFIR (calculations based on two group theory, using a $\emptyset_{\text {th }}=2.0 \times 10^{15} \mathrm{n} \cdot \mathrm{cm}^{-2} \cdot \mathrm{s}^{-1}$ and $\varnothing_{\text {th }} /$ epi-thermal $\left.=25\right)$.

Fig. 3: Mass distribution of ${ }^{228}$ Ra target before irradiation (upper) and Th fraction in ${ }^{228}$ Ra target after irradiation and separation of Th (lower).

Fig. 4: Experimental and theoretical yields of ${ }^{228} \mathrm{Th},{ }^{227} \mathrm{Ac},{ }^{228} \mathrm{Ra}$ and ${ }^{229} \mathrm{Th}$ from ${ }^{226} \mathrm{Ra}$ irradiation at the ORNL HFIR.

Fig. 5: Experimental and theoretical yields of ${ }^{228} \mathrm{Th}$ and ${ }^{229} \mathrm{Th}$ from ${ }^{227} \mathrm{Ac}$ irradiation at the ORNL HFIR.

Fig. A1: Typical $\gamma$-ray spectra of irradiated Ra target (top) and purified Th fraction (bottom). Top: spectrum (50-350 keV energy range) of one the ${ }^{226} \mathrm{Ra}$ target $(29.4 \mu \mathrm{g})$ irradiated for 9 days and cooled for about a month. Spectrum was taken for 5 hours at $60 \mathrm{~cm}$ from detector with $\sim 3 \%$ detector dead time. As indicated, all photo peaks can be attributed to ${ }^{226} \mathrm{Ra}$ target (and it decay daughters), and to ${ }^{227} \mathrm{Ac}$ and ${ }^{228} \mathrm{Th}$ decay chain. Bottom: spectrum (same energy range) of typical Th fraction purified from ${ }^{226} \mathrm{Ra}$ and ${ }^{227} \mathrm{Ac}$. This sample was then allowed to stand for $\sim 6$ months in order for $18.7-\mathrm{d}{ }^{227} \mathrm{Th}\left({ }^{227} \mathrm{Ac}\right.$ daughter) to decay. Just prior to taking the spectrum, $>99 \%$ of the ${ }^{212} \mathrm{~Pb}$ was removed by chemical processing and spectrum was taken within a 12-h window (see Experimental). This spectrum was taken for 3 hours and sample was counted at $10 \mathrm{~cm}$ from detector with $7.5 \%$ dead time

\section{CAPTIONS TO TABLES}

Table I. Hydraulic tube fluxes by axial location

Table II. Sensitivity and uncertainty of nuclear data

Table III. Composition and irradiation conditions for targets used in this study 
Table IV. ${ }^{227}$ Ac yield from ${ }^{226}$ Ra target as a function of irradiation time

Table V. ${ }^{228}$ Th yield from ${ }^{226} \mathrm{Ra}$ and ${ }^{227}$ Ac targets

Table VI. ${ }^{229}$ Th yield from ${ }^{226}$ Ra and ${ }^{227}$ Ac targets

Table VII. Yield of ${ }^{228} \mathrm{Ra}$ from ${ }^{226} \mathrm{Ra}$ target

Table VIII. Yields of thorium isotopes from ${ }^{228} \mathrm{Ra} /{ }^{226} \mathrm{Ra}$ target 


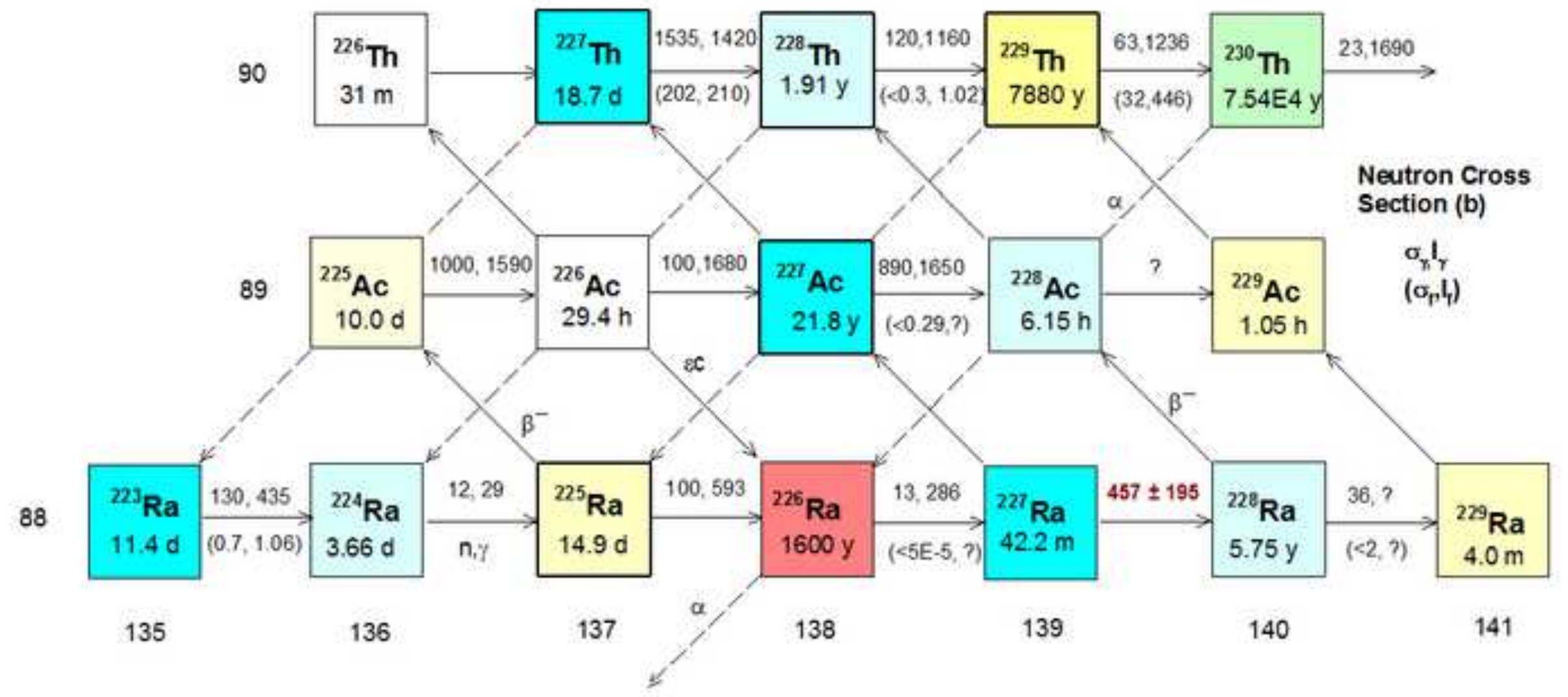




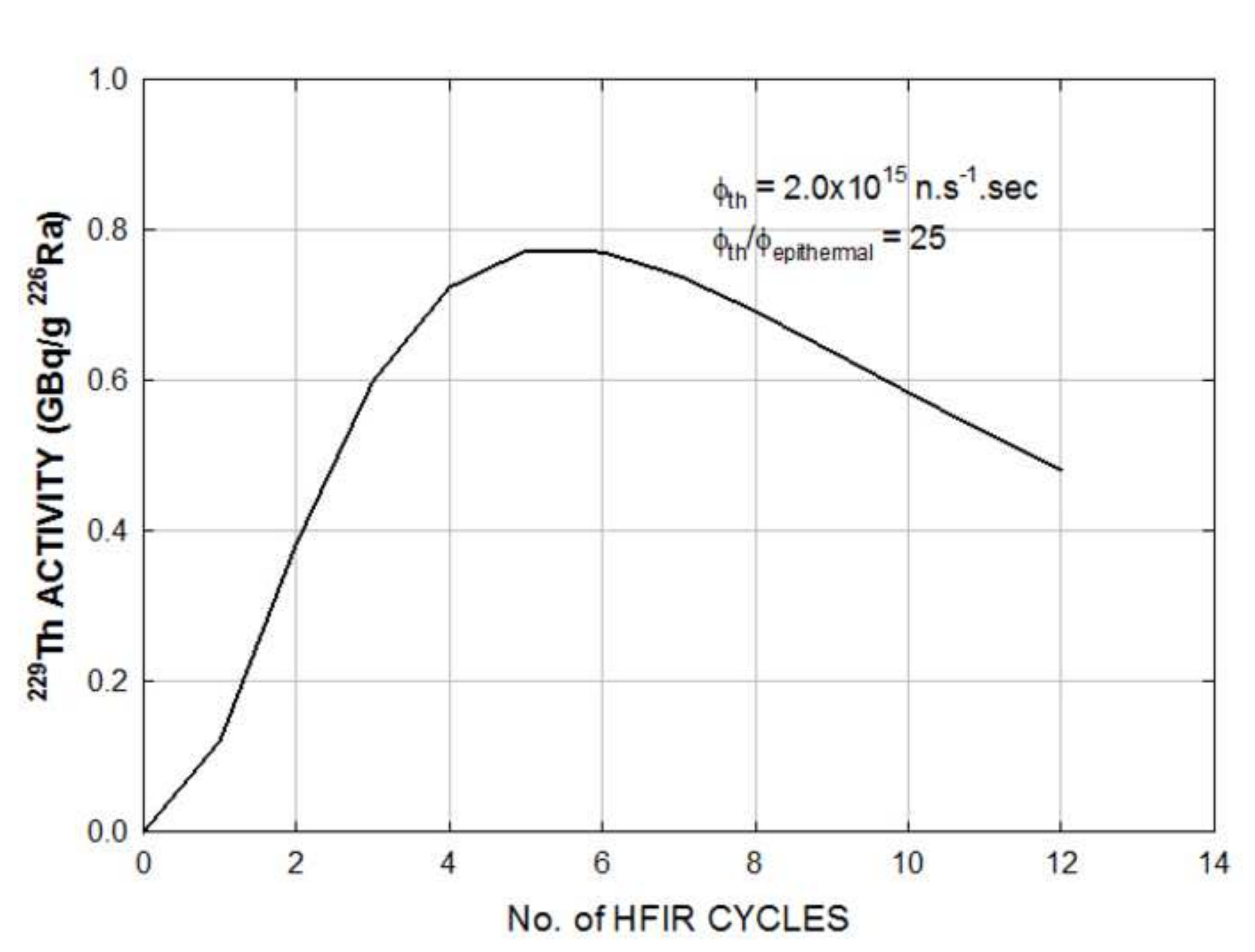

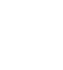

(

4

\author{
NO. OFHFIR CYCLES
}

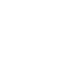
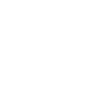

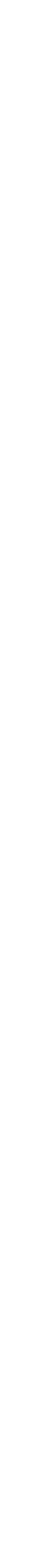




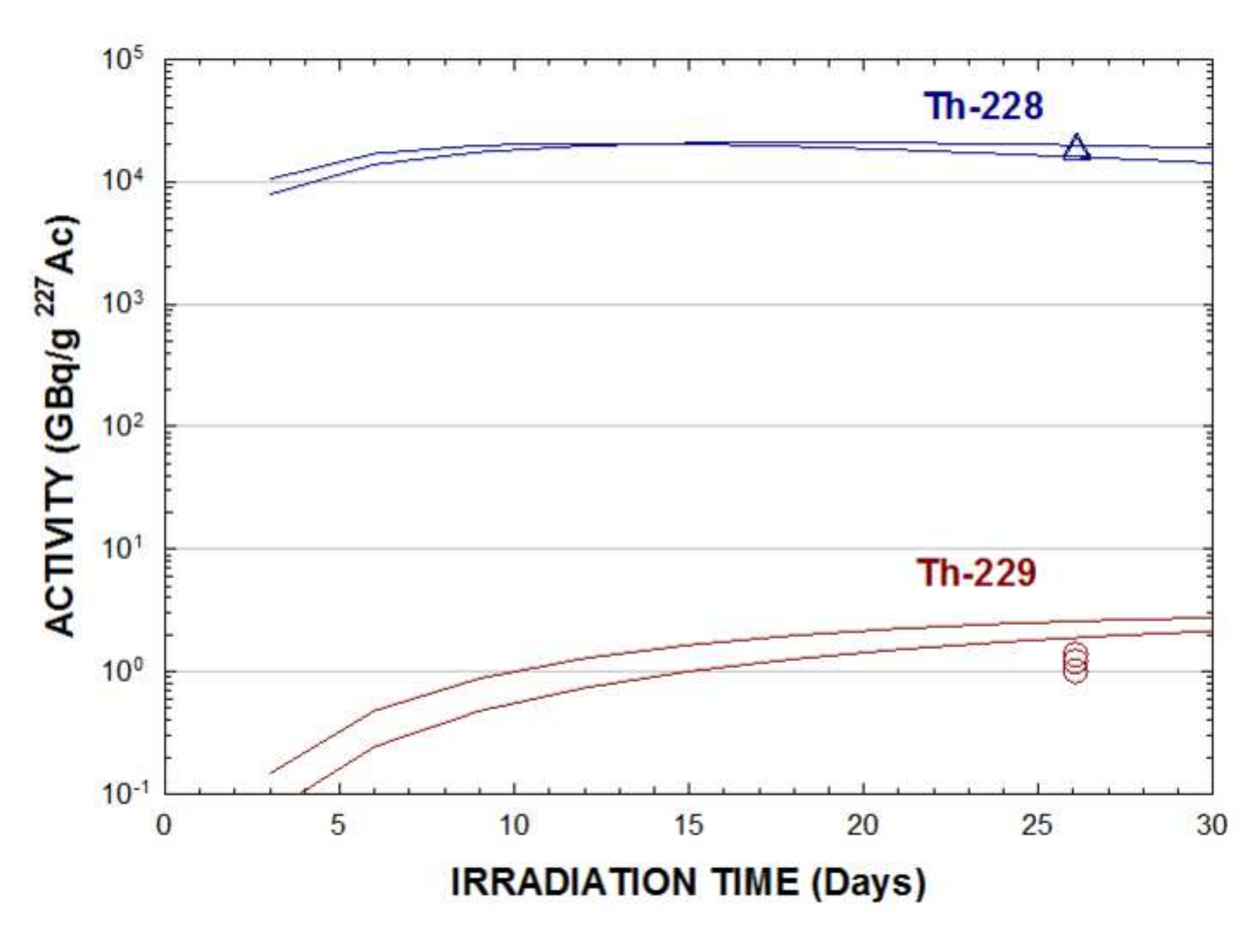

IRRADIATION TIME (Days)

0

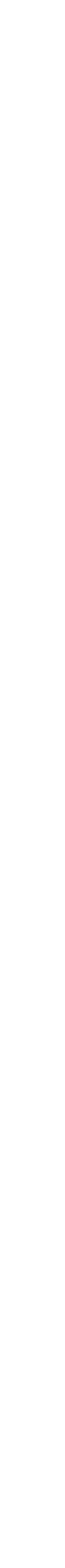


FigureA1
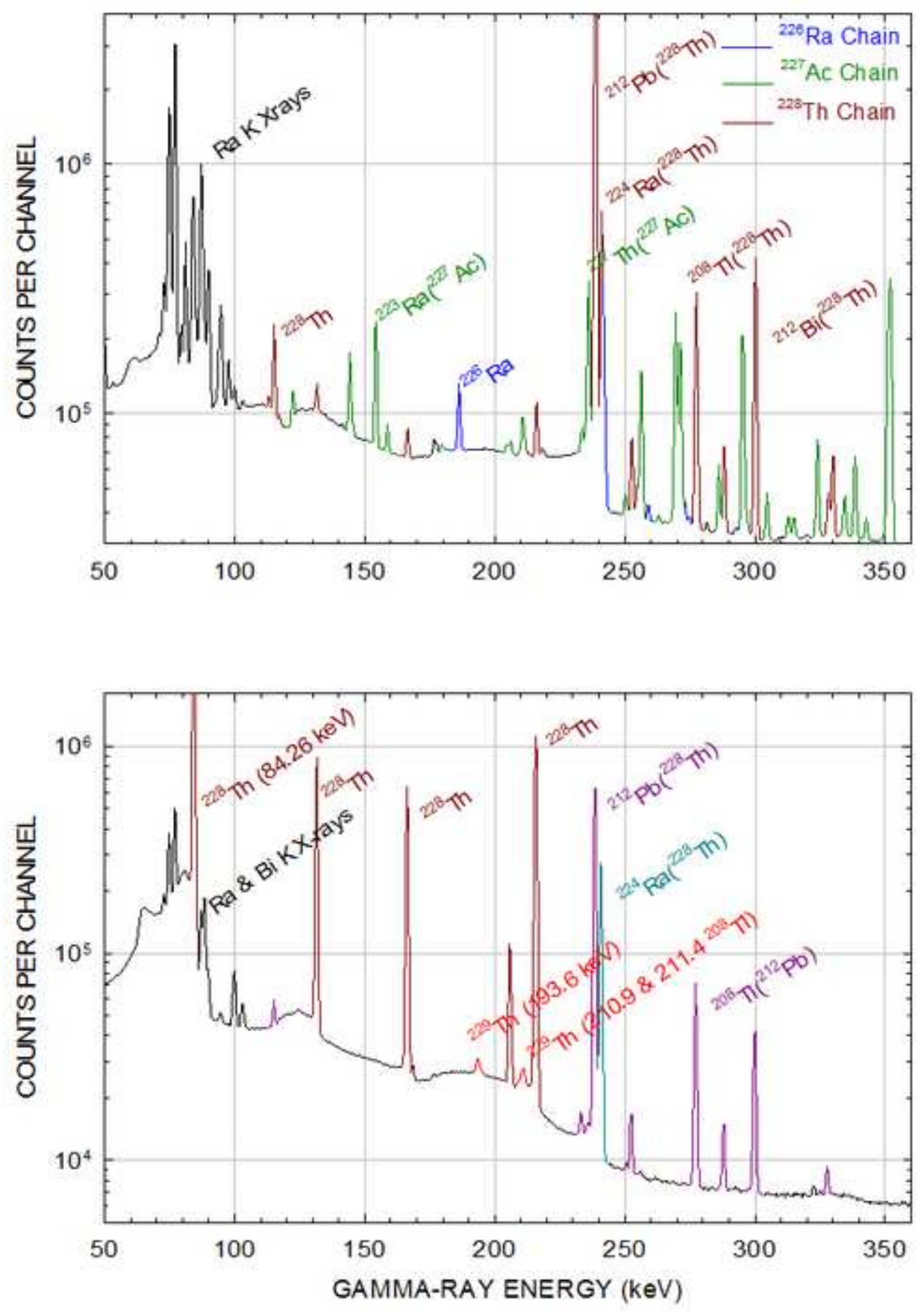